\title{
ANÁLISE PRELIMINAR DA SUCESSÃO DE TIPOS DE TEMPO NO NORTE DE MINAS GERAIS E SUAS RELAÇÕES COM OS SISTEMAS ATMOSFÉRICOS ATUANTES : PERÍODOS CHUVOSOS DE 1978/79 E 1984/85
}

\author{
Bernardo Machado Gontijo(*) \& Wellington Lopes Assis(**)
}

\section{INTRODUÇÃO}

No final da década de 70 , mais precisamente entre outubro de 78 e março de 79 , e em meados da década de 80 , entre outubro de 84 e março de 85 , ocorreram fortes eventos pluviais concentrados em todo o sudeste brasileiro, com destaque para os Estados de Minas Gerais e Espírito Santo, causando inúmeros danos à população desta região. Sabe-se que grande parte destas chuvas tiveram sua gênese em função da intensa penetração de sistemas frontais e da atuação de calhas induzidas, relacionadas a mecanismos frontais estacionários. Os períodos ora avaliados foram caracterizados pela excepcionalidade em termos de quantidade e distribuição temporal de chuvas.

Para melhor compreensão do quadro climático da época e também para um diagnóstico mais pormenorizado, resolveu-se fazer um estudo comparativo entre os tipos de tempos observados no norte de Minas Gerais com a situação observada na região central do Estado, mais precisamente com a cidade de Belo Horizonte, relacionando-os com os sistemas atmosféricos que atuaram nos períodos analisados. A região norte do Estado é caracterizada pela irregularidade na disponibilidade hídrica e por longos períodos de secas, que trazem sérios problemas para a economia e para população local. Os municípios escolhidos para este estudo possuem aproximadamente a mesma longitude, mas latitudes diferentes. Obedecendo um sentido norte-sul foram analisados os dados das localidades de Mocambinho, Montes Claros, Diamantina, Curvelo e Belo Horizonte.

Este estudo teve como objetivo a análise dos diferentes elementos do clima regional no seu ritmo de sucessão habitual, a partir da análise de dois períodos chuvosos (primavera/verão), ocorridos entre 01/10/78 e 31/03/79 e entre 01/10/84 e 31/03/85. Procurou-se, com isso, identificar e compreender aqueles mecanismos atmosféricos que estariam definindo o maior ou menor aporte de chuvas para a região em estudo. Este trabalho complementa aquele realizado por FERREIRA (1996), o qual ateve-se aos eventos pluviais concentrados em Belo Horizonte para os mesmos períodos analisados. Procurou-se, aqui, ampliar a área objeto de estudo, incluindo-se de maneira destacada a perspectiva regional, a qual permite que os sistemas atmosféricos de meso e larga escala sejam analisados de maneira mais apropriada. Em sua análise, FERREIRA (op. cit.) verificou que a sucessão habitual dos tipos de tempo, naqueles intervalos semestrais, foi marcada pela penetração de sistemas frontais, seguida pela penetração das massas polares e, finalmente, pela atuação das massas tropicais, estas últimas, às vezes intercaladas com calhas induzidas. Neste trabalho, aqueles sistemas que atuaram especificamente em Belo Horizonte são comparados aos que atuaram em todo norte de Minas, verificando-se algumas diferenças de tempo de permanência dos sistemas atuantes, principalmente em função da posição latitudinal do norte mineiro. Tal posição coloca-o mais vulnerável à atuação das massas tropicais intercaladas por calhas induzidas, e menos vulnerável à atuação dos sistemas frontais associados à penetração das massas polares.

Este trabalho deverá prosseguir no sentido de se estabelecerem correlações com as disponibilidades/ deficiências hídricas do norte mineiro, incluindo a montagem de um banco de dados. Após esta etapa, serão montados novas tabelas e gráficos, além de mapas temáticos, para melhor caracterização das variáveis climáticas atuantes nos períodos analisados.

\section{LOCALIZAÇÃO}

Para compreensão dos processos atmosféricos que atuam ou caracterizam o clima de uma determinada região é necessário que se conheçam os fatores de ordem estática que são responsáveis pela diferenciação climática intra-regional. Neste trabalho foram considerados aqueles que exercem influência a nível regional, quais sejam, a posição geográfica, a orografia e a continentalidade. Estes fatores estáticos tiveram grande importância na definição e caracterização dos tipos de tempo que atuaram nos períodos analisados. Também foram responsáveis pela definição da intensidade da participação dos sistemas atmosféricos de larga e meso escala, geradores dos eventos pluviais concentrados.

A posição geográfica da área de estudo obedece, como dito anteriormente, um perfil longitudinal nortesul, abrangendo as localidades de Mocambinho, $15^{\circ}$ $03^{\prime} \mathrm{S}$ e $44^{\circ} 56^{\prime} \mathrm{W}$, Montes Claros, $16^{\circ} 433^{\prime} 32^{\prime \prime} \mathrm{S}$ e $43^{\circ}$ 51' 52" W, Diamantina, $18^{\circ} 14^{\prime} 18^{\prime \prime}$ S e $43^{\circ} 36^{\prime} 06^{\prime \prime} \mathrm{W}$, 
Curvelo, $18^{\circ} 45^{\prime} 40^{\prime \prime} \mathrm{S}$ e $44^{\circ} 25^{\prime} 46^{\prime \prime}$ W e Belo Horizonte, $19^{\circ} 55^{\prime} \mathrm{S}$ e $43^{\circ} 56^{\prime} \mathrm{W}$, todos possuindo aproximadamente a mesma longitude, diferenciando porém em latitude. De acordo com este posicionamento geográfico a região está inserida dentro dos Climas Tropicais Quentes e Úmidos (IBGE, 1994), ocorrendo entretanto a presença de Climas Tropicais Secos e Sub-úmidos na porção mais setentrional da área analisada, na qual está inserida a localidade de Mocambinho.

Com relação a orografia, em especial às características hipsométricas, a região apresenta variações topográficas significantes. Isto resulta também em uma influência diferenciada na direção das linhas morfoclimáticas e no comportamento dinâmico dos elementos climáticos. Em termos macroregionais existem basicamente duas grandes unidades geomorfológicas que permeiam a área de estudo: a unidade das Serras e Planaltos do Leste e do Sul, abrangendo o município de Diamantina e a porção sul do município de Belo Horizonte, e a unidade da Depressão com Planaltos Residuais do São Francisco, onde estão localizados Mocambinho, Montes Claros, Curvelo e parte do sítio urbano de Belo Horizonte.

No âmbito da área de estudo, a primeira unidade é composta pelo Quadrilátero Ferrífero e pela Serra do Espinhaço, caracterizados pela presença de serras, escarpas abruptas, chapadas, pediplanos, depressões intermontanas, planícies fluviais e relevos ruiniformes. Esta unidade é muito importante tanto na diferenciação climática, ocorrendo variações microclimáticas entre os pontos de maior amplitude altimétrica, como alteração na dinâmica atmosférica de mesoescala. Esta última é influenciada pelas serras e pelos altiplanos que funcionam como barreiras orográficas na passagem de massas de ar, gerando intensa nebulosidade e chuvas em certas épocas do ano.

A segunda unidade geomorfológica é composta basicamente pela Depressão San Franciscana e pelos Planaltos do São Francisco, no qual encontram-se formas do tipo inselbergs, pediplanos, maciçosinselbergs, chapadas, depressões intermontanas, planícies fluviais, dunas entre outros. A influência desta unidade no clima, além da diversificação microclimática, está relacionada principalmente ao comportamento diário dos parâmetros meteorológicos, em especial à temperatura e à umidade relativa. A temperatura é geralmente superior a $20^{\circ} \mathrm{C}$ e a umidade relativa mantém-se baixa. Isto porque esta unidade apresenta menores altitudes e superfícies com menos rugosidade e cortes abruptos, fazendo com que a incidência de raios solares seja mais homogênea. Podese inferir também que ela apresenta-se como uma grande calha que age como canalizadora, ou mesmo direcionadora, das massas de ar que originam-se ao sul da área em estudo e que penetram nela a partir das cabeceiras do Rio São Francisco.
Quanto ao efeito da Continentalidade, este se faz presente nos municípios de Curvelo, Montes Claros e Mocambinho, principalmente no que diz respeito ao comportamento da amplitude térmica. Belo Horizonte e Diamantina apesar de estarem distante da faixa oceânica, aproximadamente uns $400 \mathrm{Km}$ em linha reta, não sofrem diretamente este efeito, pois o mesmo é amenizado pelo fator altitude. Vale a pena lembrar que a altitude média de Belo Horizonte é de $870 \mathrm{~m}$ e a de Diamantina é de $1250 \mathrm{~m}$ em relação ao nível do mar, considerada esta a sede municipal mais alta de Minas Gerais.

\section{METODOLOGIA}

A elaboração deste estudo foi possível pela análise dos diferentes elementos do clima regional no seu ritmo de sucessão habitual, a partir da análise de dois períodos chuvosos (primavera/verão), ocorridos entre 01/10/78 e 31/03/79 e entre 01/10/84 e 31/03/85. O estudo foi realizado através da coleta de dados de parâmetros meteorológicos fundamentais para a compreensão/definição dos tipos de tempo ocorridos - temperatura (incluindo máximas e mínimas), pluviosidade, umidade relativa, pressão, nebulosidade, evaporação e direção dos ventos - juntamente com a análise das cartas sinóticas, referentes ao comportamento diário dos grandes sistemas de circulação atmosférica que atuaram na região. Tanto os parâmetros meteorológicos quanto as cartas sinóticas referem-se ao horário de 12hs GTM.

A coleta dos dados foi feita tendo como base a disponibilidade dos mesmos e a localização das estações meteorológicas, procurando-se obedecer uma seqüência longitudinal, começando por Belo Horizonte e indo em direção à localidade de Mocambinho, situado no limite norte do Estado. Além destes, foi utilizada alguma bibliografia como suporte teóricometodológico para a pesquisa, em especial os trabalhos do prof. Carlos Augusto de Figueiredo Monteiro (1969, 1971).

Após a coleta dos dados foram montadas tabelas e confeccionados gráficos de análise rítmica (que não constam neste resumo por questão de aproveitamento de espaço) para cada cidade, nos dois períodos estudados, pois através destes foi possível associar a variação dos elementos do clima e os tipos de tempo que se sucederam segundo os mecanismos da circulação regional. Passada esta etapa, foi feita uma análise global entre os dados meteorológicos e as cartas sinóticas, identificando-se os tipos de tempo que atuaram com maior frequiência nos períodos analisados e os sistemas atmosféricos (utilizou-se, para tanto, a nomenclatura adotada por NIMER, 1979) responsáveis pelas condições adversas de tempo. Procurou-se, com isso, identificar e compreender aqueles mecanismos atmosféricos que estariam definindo o maior ou menor aporte de chuvas para a região em estudo. 


\section{ANÁLISE PRELIMINAR DA SUCESSÃO DOS TIPOS DE TEMPO NO CENTRO-NORTE DE MINAS GERAIS}

A identificação dos sistemas atmosféricos que atuaram nas quatros localidades (Curvelo, Diamantina, Montes Claros e Mocambinho) nos dois períodos analisados pôde ser feita pela utilização dos gráficos de análise rítmica que forneceram subsídios para melhor visualização e compreensão das sucessões dos tipos de tempo. Porém, durante o processo de análise das cartas sinóticas, as condições de tempo nem sempre se mostraram totalmente claras, ocorrendo tipos transicionais que complicaram o processo de identificação dos sistemas atmosféricos atuantes. Por este motivo, resolveu-se optar por aqueles responsáveis pela gênese dos tipos de tempo "adversos", ou seja, por aqueles sistemas que geraram precipitações.

\section{Período 1978/1979}

Conforme demonstra a gráfico 1, o sistema atmosférico responsável pela maioria dos tipos de tempo, entre outubro de 1978 a março 1979, nas quatro localidades analisadas, foi a Massa Tropical Atlântica (mTa). Em Curvelo a participação deste sistema ficou em torno dos $29.7 \%$, em Diamantina 31.0\%, em Montes Claros $33.5 \%$ e em Mocambinho $41 \%$. No domínio da atuação da mTa, verificaram-se condições de tempo estável, apresentando umidade relativa baixa, pressões relativamente altas e constantes e temperaturas elevadas. Esporadicamente, porém raramente, verificaram-se chuvas de caráter convectivo. Devido ao estacionamento deste sistema por alguns dias sobre o continente, este passava a adquirir características de continentalização, apresentando temperaturas ainda mais elevadas, com baixas índices de umidade relativa, e pressão em declínio. Devido a estas características denominou-se esta "variação" da mTa de Massa Tropical Atlântica Continentalizada (mTac). A atuação da mTac na constituição dos tipos de tempo no período 1 girou em torno dos $6.6 \%$ para Curvelo, $6.9 \%$ para Diamantina, e $7.1 \%$ para Montes Claros e Mocambinho.

A Massa Tropical Continental (mTc), associada à Baixa do Chaco, praticamente não exerceu grandes influências sobre as condições de tempo observadas nas quatro localidades. Durante todo o período foram identificados apenas duas participações em Curvelo e Diamantina e quatro em Montes Claros e Mocambinho, apresentando em seu domínio altas temperaturas e chuvas convectivas, totalizando um total de $81.8 \mathrm{~mm}$ para as 4 localidades.

A atuação das Calhas Induzidas (CI), ou linhas de instabilidade, na constituição dos tipos de tempo para a quatro localidades teve um papel importante, em especial na gênese das precipitações. Foi o segundo sistema de maior participação, registrando-se índices em torno dos $21.4 \%$ em Curvelo, $26.4 \%$ em Diamantina, e $30.2 \%$ para Montes Claros e Mocambinho. Apesar de ter sido verificado uma maior participação deste sistema nos chamados "sistemas geradores de precipitação", este, em termos de volume pluviométrico, foi bem menor se comparado com os totais registrados pela atuação dos sistemas frontais.

As invasões da Frente Polar Atlântica (FPA) nas quatro localidades, durante este período, caracterizaram-se por um aumento generalizado da nebulosidade, queda de pressão, queda de temperatura, elevada umidade relativa e presença de chuvas de intensidade variada. Como dito anteriormente, elas foram responsáveis pelos maiores índices pluviométricos, principalmente nos totais diários. Somando-se a atuação da FPA e da Frente Polar Atlântica Estacionária (FPAe) tem-se índices pluviométricos de $1015 \mathrm{~mm}$ para Curvelo, $907 . \mathrm{mm}$ para Diamantina, $698.5 \mathrm{~mm}$ para Montes Claros e $499.9 \mathrm{~mm}$ para Mocambinho. Com a simples chegada da FPA no sul do país mudavam-se as condições de tempo na região em estudo, seja em forma de Repercussão Vanguardeira (RV) ou CI (Calhas Induzidas).

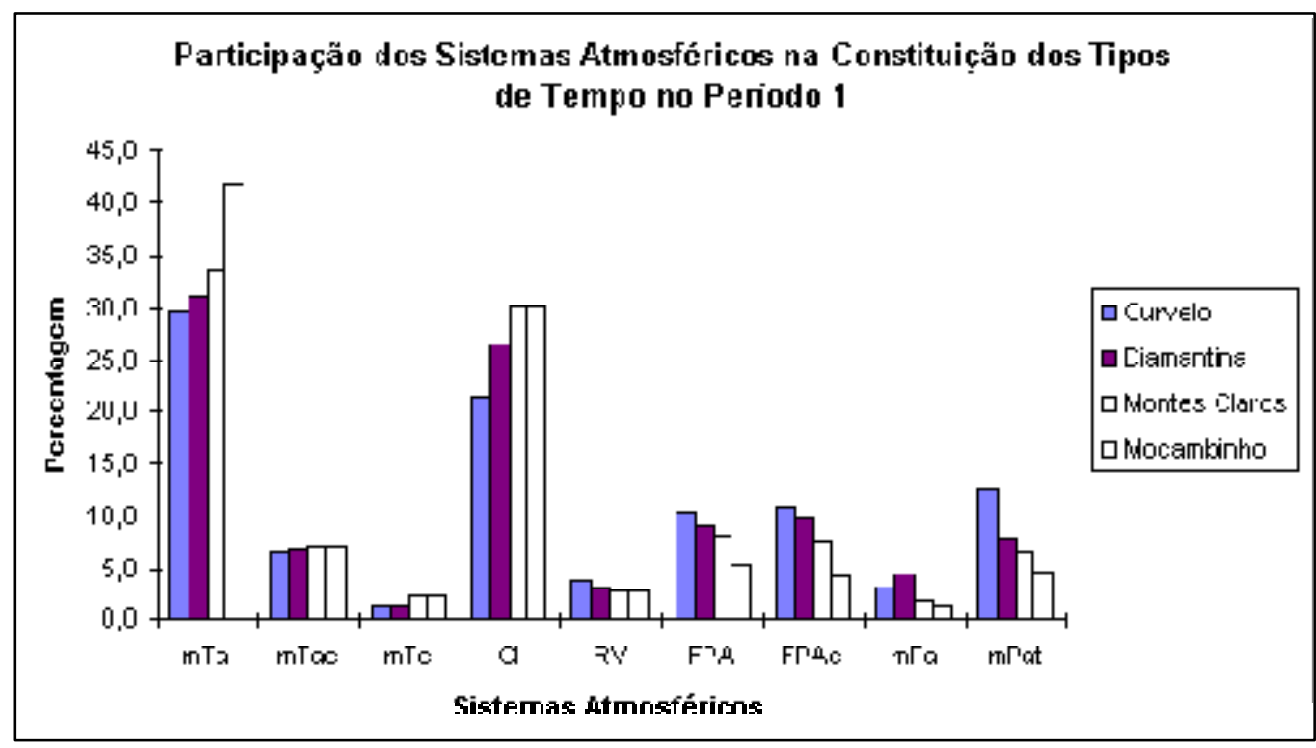

Gráficol 
A participação da Massa Polar Atlântica (mPa) na constituição dos tipos de tempo durante o período foi bem tímida, a sua atuação ficou em torno dos $3.3 \%$ em Curvelo, $4.6 \%$ em Diamantina, $1.6 \%$ em Montes Claros e $1.1 \%$ em Mocambinho (os valores maiores para Diamantina podem ser explicados pela altitude, que manteria, ou reforçaria, as baixas temperaturas que ocorrem no âmbito das massas polares) . Basicamente sob seu domínio os tipos de tempo apresentaram-se relativamente estáveis. O fato de apresentarem, não raramente, céu nublado mas com poucas chuvas e taxas de umidade relativa elevada pode ser explicado pela maturidade com que tais massas chegam à Minas Gerais, muitas delas já em adiantado processo de tropicalização. O estacionamento dessa massa sobre o continente por alguns dias, também faz com que ela passe a adquirir características de tropicalização (Massa Polar Atlântica Tropicalizada - mPat).

\section{Período 1984/1985}

De acordo com a gráfico 2, a Massa Tropical Atlântica (mTa) foi o sistema atmosférico responsável pela maioria dos tipos de tempo analisados nas quatros localidades, entre outubro de 1984 a março 1985. Sua atuação em termos relativos foi menor se comparada com o período anterior. Curvelo e Diamantina registraram índices de participação de $26.9 \%$, Montes Claros ficou em torno dos $33.5 \%$ e Mocambinho 36.8\%. Sob seu domínio as condições de tempo eram estáveis, apresentando baixas taxas de umidade relativa, alta pressão e temperaturas elevadas. A participação deste sistema na gênese de chuvas foi extremamente pequena, a maior parte de caráter convectivo. Somando-se os dias temos apenas 6 durante todo o período, com um total pluviométrico de $3.5 \mathrm{~mm}$. A "versão" continentalizada da mTa, mTac, teve uma atuação de $6.0 \%$ para todas as quatros localidade e apenas 2 dias de chuvas foram registrados sob o seu domínio.

Apesar de uma participação tímida da Massa Tropical Continental (mTc) na constituição dos tipos de tempo (cerca de $7.1 \%$ para Curvelo, $6.0 \%$ para Diamantina, $8.8 \%$ para Montes Claros e $10.9 \%$ para Mocambinho), esta , em associação com a penetração dos sistemas frontais, foi responsável secundariamente pelos maiores índices pluviométricos registrados neste período. Isto ocorria devido as condições de instabilidade condicional proporcionada pelas altas temperaturas e umidade relativa da $\mathrm{mTc}$, que geraram condições "ótimas" de condensação e precipitação. Este processo "acelerava-se" a medida que penetravam os sistemas frontais no sul do país, resultando em intensas chuvas. O estacionamento das FPA sobre o Continente (FPAe), agravava este quadro de tempo chuvoso, ocorrendo o aparecimento de grande número de linhas de instabilidade sobre a região de estudo, geralmente Calhas Induzidas. A associação entre sistemas frontais e instabilidade condicional dentro da região centro-sul do país é chamada pela literatura meteorológica de ZCAS (Zona de Convergência do Atlântico Sul) (ABREU,1997, comunicação pessoal).

As Calhas Induzidas (CI) foram o segundo sistema de maior atuação na constituição dos tipos de tempo,

Gráfico 2

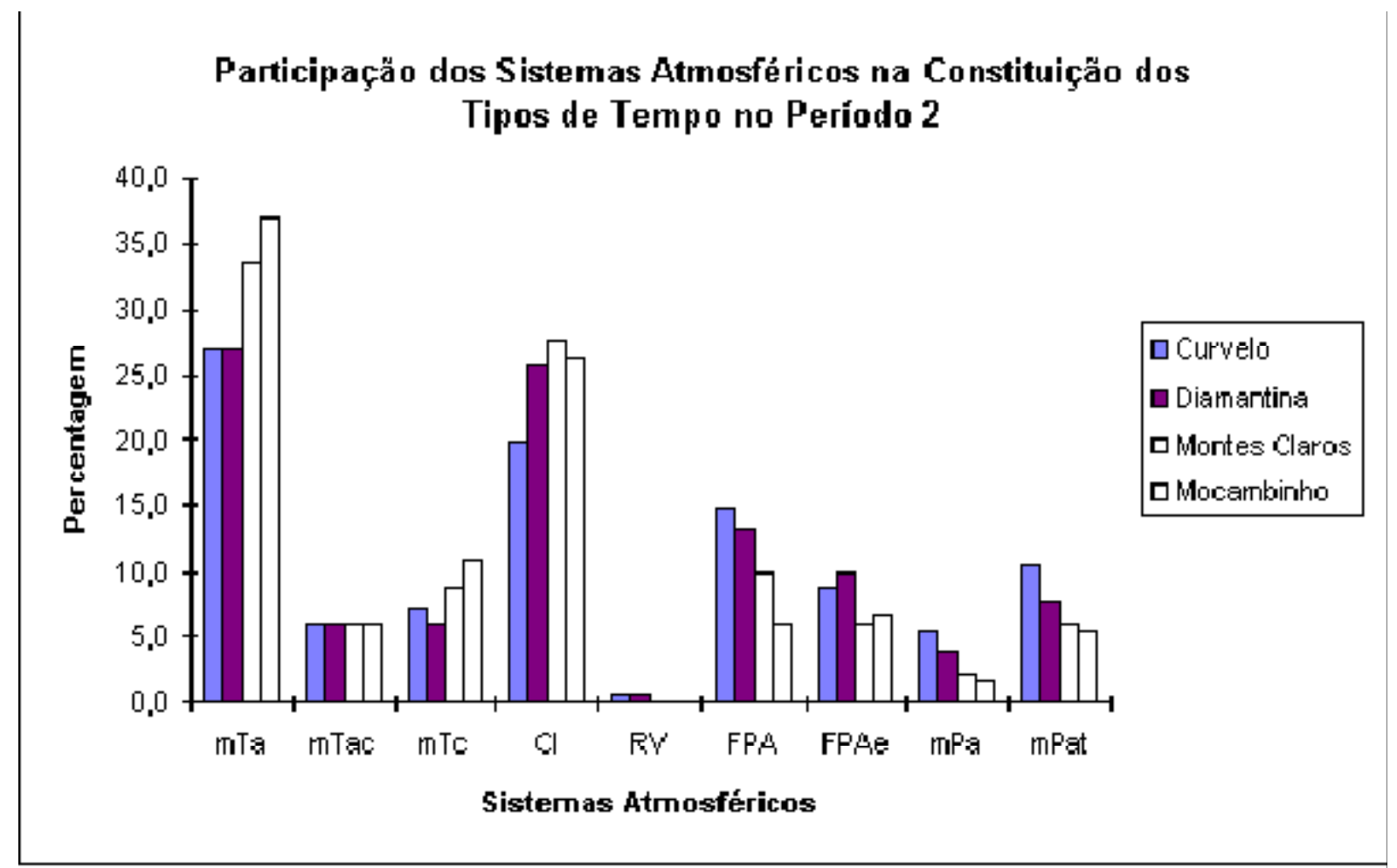


como também na gênese dos principais eventos pluviométricos. Ao todo foram 36 dias de participação em Curvelo, 47 em Diamantina, 50 em Montes Claros e 48 em Mocambinho. O total pluviométrico durante todo o período, para as quatros cidades, foi de 1537.3 $\mathrm{mm}$.

Assim como as Calhas Induzidas, as invasões da Frente Polar Atlântica (FPA) tiveram um papel primordial na gênese dos principais eventos pluviométricos, principalmente em termos volumétricos. Ao todo este sistema proporcionou 27 dias de chuva em Curvelo, 24 em Diamantina, 18 em Montes Claros e 11 em Mocambinho. Somando-se a participação da FPA e da FPAe, tem-se índices pluviométricos de $918.2 \mathrm{~mm}$ para Curvelo, $1012.2 \mathrm{~mm}$ para Diamantina, $615 \mathrm{~mm}$ para Montes Claros e 512.1 mm para Mocambinho.

Da mesma maneira que no primeiro período, outubro de 1978 a março 1979, a participação da mPa e de sua versão tropicalizada (mPat) neste segundo período foi bem tímida. Somando-se os dois sistemas temos as seguintes taxas: Curvelo $15.9 \%$, Diamantina $11.5 \%$, Montes Claros $8.2 \%$ e Mocambinho $6.6 \%$. No domínio da $\mathrm{mPa}$ os tipos de tempo eram relativamente estáveis, apresentando na maioria das vezes céu nublado em função da tropicalização, mas com poucas chuvas.

\section{CONSIDERAÇÕES FINAIS}

Pode-se dizer, de uma maneira geral, que mTa foi o principal sistemas atmosférico na constituição dos tipos de tempo para os dois períodos analisados. No que diz respeito aos sistemas geradores de precipitação, tem-se que no primeiro período as chuvas foram causadas pela participação dos sistemas frontais e das Calhas Induzidas, seguidos pelas massa polares. No segundo período as precipitações foram causadas pela associação da instabilidade condicional, proporcionada pela mTc, e pela atuação das Frentes Frias vindas do Atlântico Sul.

Ao observarmos as duas figuras, nota-se a tendência geral de diminuição da atuação da mTa à medida em que aumenta-se a latitude, ou seja, Mocambinho, mais ao norte, já na transição para o semi-árido, é mais influenciada pela mTa do que Curvelo, considerado centro geográfico de Minas Gerais. Situação inversa pode ser percebida com relação à atuação das frentes frias e os sistemas a elas associados. A atuação delas é sempre mais freqüente nas localidades de maiores latitudes, primeiras a sofrerem seus efeitos no âmbito da região em estudo.

A análise geral dos parâmetros meteorológicos considerados neste trabalho, principalmente com relação aos gráficos de análise rítmica, reflete nitidamente o efeito da posição elevada, em termos altimétricos, de Diamantina. A altitude desta cidade reduz sobremaneira suas médias de temperatura e aumenta seus volumes pluviométricos (e consequentemente a nebulosidade e a umidade relativa). Ao mesmo tempo em que isto "mascara" o efeito que se podia esperar da posição latitudinal de Diamantina (mais ao norte do que Curvelo), isto revela a marcante influência exercida pela orografia, no caso a porção meridional da Serra do Espinhaço, para a definição do clima local (e regional).

Com relação às duas localidades localizadas mais ao norte, percebe-se a influência maior da continentalidade e o caráter climático transicional do norte mineiro. Tanto em Montes Claros como em Mocambinho a influência da semi aridez se faz notar, principalmente com relação ao menor volume das chuvas e na maior irregularidade dessas, e com relação às maiores médias térmicas. $\mathrm{O}$ estudo das disponibilidades hídricas para tais localidades também revela a tendência para a semi-aridez, motivo pelo qual a análise das variáveis relacionadas ao balanço hídrico será objeto de um estudo mais aprofundado e que dará continuidade àqueles até aqui realizados.

\section{BIBLIOGRAFIA CONSULTADA}

FERREIRA, Vanderlei de Oliveira. Eventos Pluviais Concentrados em Belo Horizonte - MG: caracterização genética e impactos físicos-ambientais. IGC -UFMG, Dissertação de Mestrado. 1996.

MONTEIRO, C. A. de F. Frente Polar Atlântica e as Chuvas de Inverno na Fachada Suboriental do Brasil. São Paulo, Série Teses e Monografia 1, USP-IG, 1969, 68p.

. Análise Rítmica em Climatologia (problemas da atualidade climática em São Paulo e achegas para um programa de Trabalho). São Paulo, Série Climatologia Dinâmica I, USP-IG, 1971, 21p.

NIMER, Edmon. Climatologia do Brasil. Rio de Janeiro; IBGE, 1979. 421p

RIBEIRO, C. M. O desenvolvimento da Climatologia Dinâmica no Brasil. Revista Geografia e Ensino, Belo Horizonte, 1 (2): 4859, set. 1982.

TARIFA, J. R. Sucessão de Tipos de Tempo e Variação do Balanço Hídrico no Extremo Oeste Paulista. São Paulo, Série Teses e Monografias 8, USP-IG, 1973, 71p. 
